\title{
Reconciling Teleseismic and Regional Estimates of Seismic Energy
}

\author{
by Xyoli Pérez-Campos, * Shri K. Singh, and Gregory C. Beroza
}

\begin{abstract}
Estimates of the radiated seismic energy based on teleseismic and regional data often differ by up to an order of magnitude, with a tendency for regional estimates to be larger than teleseismic estimates for the same event. In this study we compare the velocity spectrum determined from teleseismic data after correction for radiation pattern and propagation effects, with the velocity spectrum determined from regional data, after the corresponding corrections, for nine earthquakes in the Middle America subduction zone of Mexico. This comparison of the corrected spectra is used to identify and reduce the sources of the regional versus teleseismic energy discrepancy, which is about an order of magnitude for these events. We find that the teleseismic attenuation operator needs to be calibrated. In our case, for the tectonic environment of the Mexican subduction zone, we need a teleseismic attenuation operator that is stronger at high frequencies than the global average. A larger factor, however, is the correction needed to account for site amplification. This correction has an impact on both regional and teleseismic data, but it has a larger influence on the regional estimates because the angle of incidence for teleseismic waves is steep and the stations are located on more competent rock. By modifying the teleseismic attenuation operator and applying site corrections based on a generic site model, we essentially eliminate the order-of-magnitude discrepancy between teleseismic and regional estimates of the radiated seismic energy for these events.
\end{abstract}

\section{Introduction}

The seismic energy is a fundamental parameter of the strength of seismic waves generated by an earthquake, and it may prove to be a critical parameter for understanding earthquake rupture dynamics. The measurement of seismic energy has become routine for large earthquakes to the point where it has been proposed as the basis for an energy magnitude, $M_{\mathrm{E}}$, by the National Earthquake Information Center (NEIC) (Choy and Boatwright, 1995). A number of studies have reported interesting dependence of the radiated energy on earthquake size (e.g., Kanamori et al., 1993; Abercrombie, 1995) and focal mechanism (e.g., Choy and Boatwright, 1995; Pérez-Campos and Beroza, 2001). Large discrepancies in energy measurements for the same earthquake using different datasets, however, suggest that large uncertainties still remain and that the interpretation of possible scaling or focal mechanism dependence may be premature.

Some authors have estimated seismic energy using teleseismic $P$-wave data (Boatwright and Choy, 1986; Kikuchi and Fukao, 1988; Newman and Okal, 1998; Pérez-Campos and Beroza, 2001), while others have used local or regional $S$-wave data (e.g., Kanamori et al., 1993; Singh and Ordaz,

*Present address: Seismological Laboratory MS 252-21, California Institute of Technology. 1200 E. California Blvd., Pasadena, California 91125.
1994). Abercrombie (1995) and Prejean and Ellsworth (2001) estimated seismic energy using $P$ and $S$ waves from borehole data, while Mayeda and Walter (1996) used regional coda waves, and Shi et al. (2000) used regional $L g$ waves. Singh and Ordaz (1994) first noted that regional estimates of the seismic energy were larger than the teleseismic estimates by up to an order of magnitude for the same event. Figure 1 demonstrates that this discrepancy persists over earthquake mechanism types and tectonic regimes, such as subduction zones or transform faults.

Different approaches have been taken to resolve this discrepancy. The Hector Mine earthquake in 1999 provided a good regional and teleseismic dataset to address this problem for a shallow strike-slip event. Venkataraman et al. (2002) used empirical Green's function deconvolution to obtain the source spectrum, then used this source spectrum to estimate the seismic energy. Boatwright et al. (2002) estimated the seismic energy of the same event from the integral of the squared velocity spectrum, but in contrast to other studies, used a geometrical spreading correction that is both frequency and distance dependent. For the teleseismic data, they adjusted the attenuation correction for shallow earthquakes in the western United States and estimated the attenuation correction for the region. They also corrected the spectrum for the site effect at the recording station. Both 


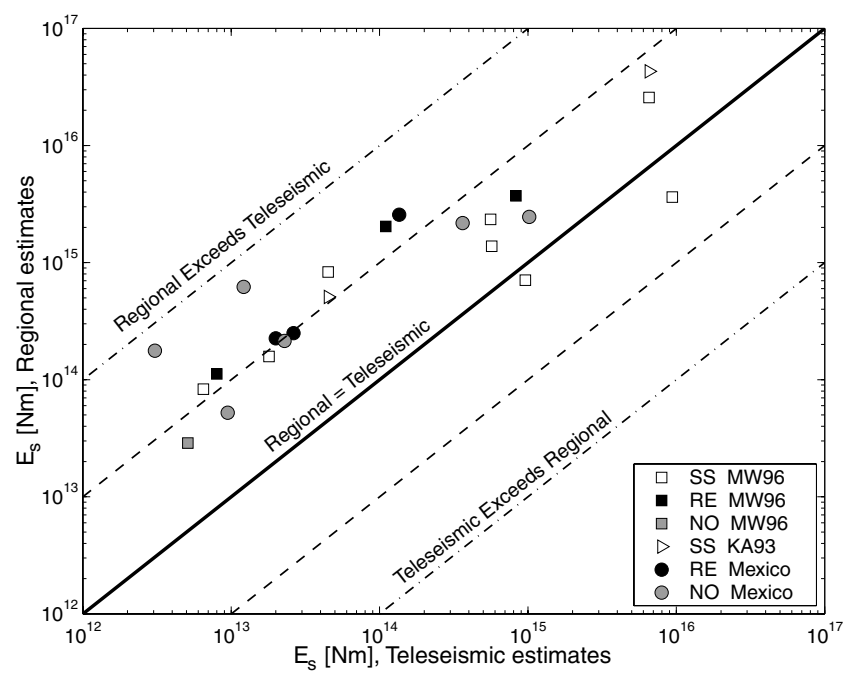

Figure 1. Regional versus teleseismic estimates of seismic energy. Open symbols represent strike-slip earthquakes (SS); black symbols, reverse earthquakes (RE); and gray symbols, normal earthquakes (NO). Regional estimates were obtained from Mayeda and Walter (1996) (MW96) and Kanamori et al. (1993) (KA93), and corresponding teleseismic values were obtained from the NEIC catalog. For the Mexican earthquakes, the focus of this article, regional values were calculated after Singh and Ordaz (1994) and teleseismic values after Pérez-Campos and Beroza (2001).

studies found close agreement between the teleseismic and the regional energy estimates, and their estimates are consistent with each other. While this agreement is encouraging, it represents only one earthquake. Rupture in this event was bilateral and at relatively low rupture velocity (Dreger and Kaverina, 2000). Thus, the Hector Mine earthquake may represent an especially favorable situation. In any case, it is important to see if the agreement holds for diverse events in other tectonic environments.

In this study we attempt to reconcile the regional and teleseismic estimates of the radiated seismic energy from nine earthquakes in the range $5.9<M_{\mathrm{w}}<7.4$. We follow the approach used by Singh and Ordaz (1994) for the regional estimate and the technique described by Boatwright and Choy (1986), as revised by Pérez-Campos and Beroza (2001), for the teleseismic estimate. We study earthquakes occurring in the subduction zone in Mexico, which provides us with good station coverage at both teleseismic and regional distances. Furthermore, we analyze data for both shallow, reverse-faulting, interplate events and the intermediatedepth, normal-faulting, intraplate events.

We use corrected velocity spectra to identify and reduce the sources of the regional versus teleseismic energy discrepancy. First, we calibrate the teleseismic attenuation operator and replace it with one that is somewhat stronger than that found for other regions. A second, and more significant correction, accounts for site effects. This correction affects both regional and teleseismic data, but has a larger impact on regional data. Together these corrections appear to account for the teleseismic versus regional seismic energy discrepancy for these events.

\section{Data}

Since the 1957 Acapulco earthquake, Mexico has installed more than 300 accelerographs, distributed mainly close to seismically active regions such as the Middle America trench and the San Andreas fault system at the northern end of the Baja California Peninsula. There is a large concentration of stations in Mexico City as well (Quass et al., 1993) due to the considerable seismic hazard faced by the country's capital. The National Seismological Service of Mexico also operates a broadband seismic network that currently consists of 25 stations. For this study, we use only the stations listed in Table 1 (Fig. 2). We choose these stations because they are all located on rock sites (Quass et al., 1993), which will minimize site effects and allow us to use a simplified generic rock site correction for all the data.

We analyze nine events (Table 2, Fig. 2) that occurred during the period 1993-1999. Three of these are reverse, shallow, and interplate, while the other six are normal, intermediate depth, and intraplate. They range in depth from 22 to $64 \mathrm{~km}$ and in magnitude from 5.9 to 7.4. In each case, the earthquakes are well-recorded both regionally and teleseismically. Standard estimates of the seismic energy for these events (Pérez-Campos and Beroza, 2001) reveal that regional estimates are uniformly higher than teleseismic estimates, sometimes by more than an order of magnitude (Fig. 1, circles). A similar tendency was observed by Singh and Ordaz (1994).

\section{Analysis}

We follow Singh and Ordaz (1994) in analyzing the $S$ wave train from records of stations at local and regional distances (within $700 \mathrm{~km}$ ). The energy flux of each component, $\varepsilon_{i}(\mathrm{~N}=$ north, $\mathrm{E}=$ east, and $\mathrm{Z}=$ vertical $)$, is estimated in the frequency domain,

$$
\varepsilon_{i}=2 \rho \beta \int_{0}^{\infty} \dot{u}_{i}^{2}(f) e^{2 \pi f R / \beta Q(f)} d f
$$

where $\rho$ and $\beta$ are the density $\left(2.8 \mathrm{~g} / \mathrm{cm}^{3}\right)$ and the shearwave velocity $(3.5 \mathrm{~km} / \mathrm{sec}), \dot{u}_{i}(f)$ is the velocity spectrum of component $i, R$ is the hypocentral distance to the station, and $Q(f)$ is the quality factor. All three components are summed to obtain the total seismic energy:

$$
E_{\mathrm{s}}=\frac{4 \pi G^{2}(R)}{F_{\mathrm{s}}^{2}} \cdot\left[\varepsilon_{\mathrm{N}}^{2}+\varepsilon_{\mathrm{E}}^{2}+\varepsilon_{\mathrm{Z}}^{2}\right]
$$

(Singh and Ordaz, 1994), where $G(R)$ is the geometrical 
Table 1

Mexican Stations Used in the Analysis

\begin{tabular}{|c|c|c|c|c|c|c|c|}
\hline No. & $\begin{array}{l}\text { Station } \\
\text { Code }\end{array}$ & Institution & Name & $\begin{array}{c}\text { Latitude } \\
\text { (deg) }\end{array}$ & $\begin{array}{l}\text { Longitude } \\
\text { (deg) }\end{array}$ & $\begin{array}{l}\text { Altitude } \\
(\mathrm{m})\end{array}$ & $\begin{array}{c}\kappa \\
(\mathrm{sec})\end{array}$ \\
\hline 1 & ACAJ & CENAPRED & Acapulco & 16.8400 & -99.8900 & 60 & 0.0306 \\
\hline 2 & ATYC & II & Atoyac & 17.2100 & -100.4310 & 40 & 0.0250 \\
\hline 3 & CAIG & IGF & Cayaco & 17.0480 & -100.2670 & 80 & 0.0306 \\
\hline 4 & CALE & II & Caleta de Campos & 18.0730 & -102.7550 & 10 & 0.0387 \\
\hline 5 & CHIL & CENAPRED & Chilpancingo & 17.4660 & -99.4520 & 1350 & 0.0306 \\
\hline 6 & COPL & II & Copala & 16.6050 & -98.9740 & 40 & 0.0358 \\
\hline 7 & COYC & II & Coyuca & 16.9680 & -100.0840 & 30 & 0.0428 \\
\hline 8 & HUIG & IGF & Huatulco & 15.7680 & -96.1080 & 150 & 0.0306 \\
\hline 9 & IGUA & CENAPRED & Iguala & 18.3990 & -99.5061 & 1350 & 0.0306 \\
\hline 10 & MEZC & CENAPRED & Mezcala & 17.9300 & -99.5900 & 1660 & 0.0306 \\
\hline 11 & OCLL & II & Ocotillo & 17.0380 & -99.8750 & 700 & 0.0266 \\
\hline 12 & OXIG & IGF & Oaxaca & 17.0720 & -96.7330 & 1600 & 0.0306 \\
\hline 13 & PET2 & II & Petatlán & 17.5420 & -101.2710 & 30 & 0.0237 \\
\hline 14 & PETA & II & Petatlán & 17.5420 & -101.2710 & 30 & 0.0237 \\
\hline 15 & PLIG & IGF & Iguala & 18.3920 & -99.5020 & 875 & 0.0306 \\
\hline 16 & PNIG & IGF & Pinotepa & 16.3923 & -98.1271 & 350 & 0.0306 \\
\hline 17 & POZU & II & Pozuelos & 17.1000 & -99.6300 & 450 & 0.0306 \\
\hline 18 & SLUI & II & San Luis de la Loma & 17.2720 & -100.8910 & 20 & 0.0221 \\
\hline 19 & TEAC & II & Teacalco & 18.6280 & -99.4530 & 1000 & 0.0486 \\
\hline 20 & TNLP & II & Tonalapa del Sur & 18.0980 & -99.5590 & 740 & 0.0368 \\
\hline 21 & UNIO & II & La Unión & 17.9820 & -101.8050 & 50 & 0.0273 \\
\hline 22 & VILE & II & Villita (right) & 18.0160 & -102.2050 & 60 & 0.0414 \\
\hline 23 & VNTA & II & La Venta & 16.9230 & -99.8160 & 60 & 0.0245 \\
\hline 24 & YAIG & IGF & Yautepec & 18.8620 & -99.0670 & 1340 & 0.0306 \\
\hline 25 & ZIIG & IGF & Zihuatanejo & 17.6070 & -101.4650 & 50 & 0.0306 \\
\hline
\end{tabular}

These stations are located on rock sites (Quass et al., 1993). CENAPRED, National Center for Disaster Prevention; IGF, Institute of Geophysics, II, Institute of Engineering, UNAM.

spreading correction, discussed later, and $F_{\mathrm{s}}$ is the freesurface amplification (which is equal to 2).

For the teleseismic estimate, we selected the $P$-wave group ( $P, p P$, and $s P$ waves) from stations at distances between $30^{\circ}$ and $90^{\circ}$, using only the vertical component and assuming the same proportion between $S$ - and $P$-wave energy, $q=15.58$, as Boatwright and Choy (1986). The estimate was obtained using modifications described in PérezCampos and Beroza (2001).

In both cases, we applied corrections for attenuation, geometrical spreading, and radiation pattern. For the regional estimate (equation 1), the attenuation is characterized by $\mathrm{e}^{-\pi f R / \beta Q(f)}$, where

$$
Q(f)=273 f^{0.66}
$$

(Ordaz and Singh, 1992); the geometrical spreading correction in this case is given by

$$
G(R)=\left\{\begin{array}{ll}
R & R \leq R_{0}=100 \mathrm{~km} \\
\sqrt{R_{0} R} & R>R_{0}=100 \mathrm{~km}
\end{array},\right.
$$

where $R_{0}$ is a crossover distance beyond which surface waves are assumed to dominate (Singh and Ordaz, 1994). Boatwright et al. (2002) used a frequency-dependent geo- metrical spreading correction, with a constant crossover distance of $27.5 \mathrm{~km}$ for the regional energy estimate of the 1999 Hector Mine earthquake; however, for reasons discussed later, we adopted the correction given by equation (4).

At teleseismic distances, the attenuation is characterized by the factor $\mathrm{e}^{-\pi f t^{*}}$, where we assumed a frequencydependent $t^{*}$ model given by

$$
t^{*}= \begin{cases}0.9-0.1 \log (f) \quad f<0.1 \mathrm{~Hz} \\ 0.5-0.5 \log (f) & 0.1<f<1.0 \mathrm{~Hz} \\ 0.5-0.1 \log (f) & 1.0<f \mathrm{~Hz}\end{cases}
$$

(Fig. 3) (Choy and Cormier, 1986).

The fundamental measurement from which we estimate the seismic energy is the integral of the squared velocity seismogram. For this reason, we compare the corrected velocity spectrum determined from regional data with that obtained from teleseismic data. In our analysis we assume that the source spectra obtained with regional and teleseismic data are equal. Based on $m_{\mathrm{b}}-M_{\mathrm{w}}$ and $m_{\mathrm{b}}(L g)-M_{\mathrm{w}}$ scaling and the saturation of $m_{\mathrm{b}}$ but not $m_{\mathrm{b}}(L g)$ (Patton, 2001), it may be argued that the apparent source spectra retrieved from teleseismic $P$ waves and regional $S$ waves differ around $1 \mathrm{~Hz}$. The difference in the scaling and the saturation of $m_{\mathrm{b}}$ may also be attributable to the fact that $m_{\mathrm{b}}$ is determined from the amplitude of first few cycles of teleseismic $P$ 


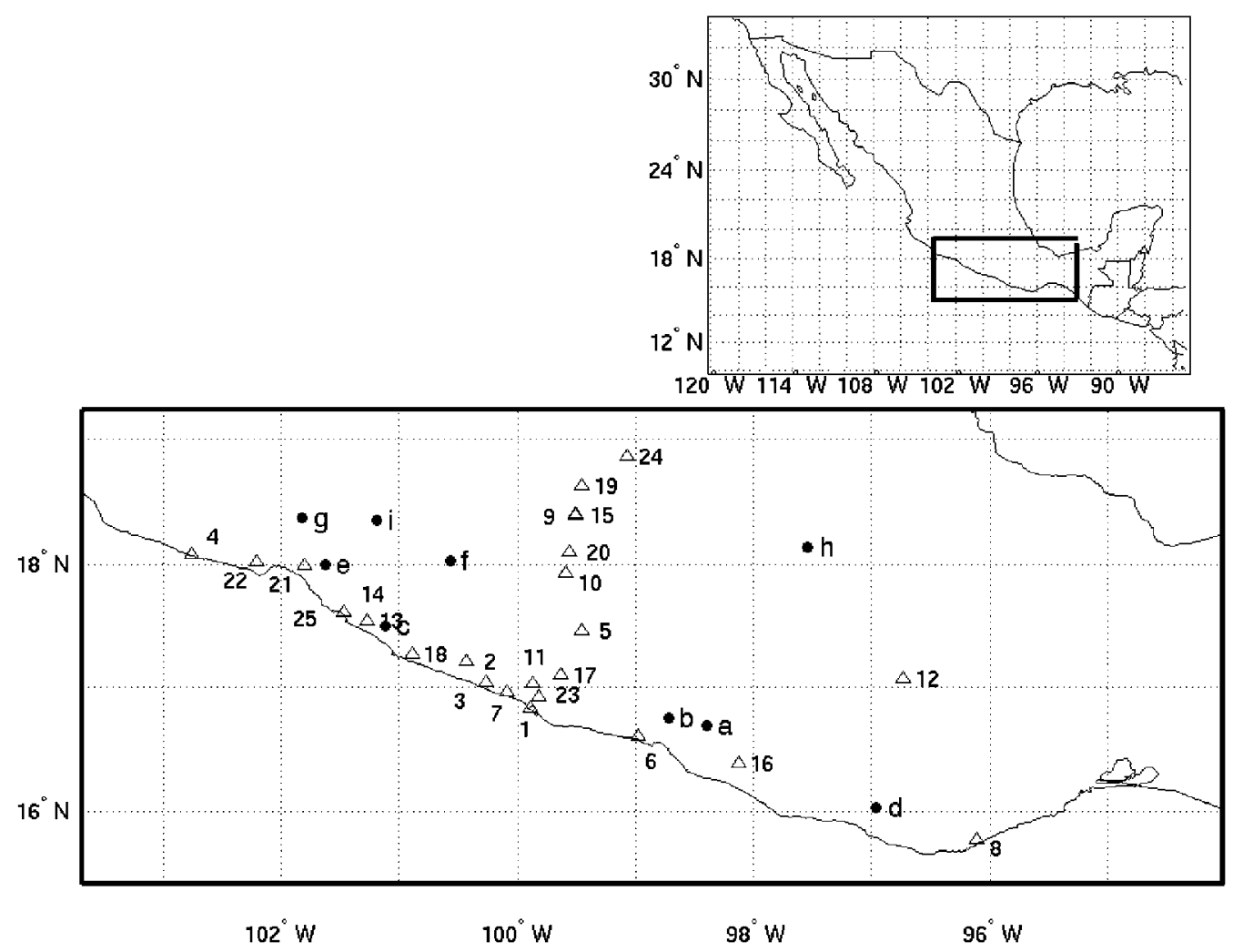

Figure 2. Locations of earthquakes and regional stations. Epicentral locations are represented by filled circles. Letters next to symbols correspond to those in Table 2. The station locations are shown as triangles, and the numbers next to them refer to those in Table 1.

Table 2

Earthquakes Analyzed

\begin{tabular}{|c|c|c|c|c|c|c|c|c|c|c|}
\hline Event & $\begin{array}{c}\text { Date } \\
\text { (yymmdd) }\end{array}$ & Mechanism & $\begin{array}{l}\text { Longitude } \\
\text { (deg) }\end{array}$ & $\begin{array}{l}\text { Latitude } \\
\text { (deg) }\end{array}$ & $\begin{array}{l}\text { Depth } \\
(\mathrm{km})\end{array}$ & $\begin{array}{c}\phi_{\mathrm{s}} \\
(\mathrm{deg})\end{array}$ & $\begin{array}{c}\delta \\
(\mathrm{deg})\end{array}$ & $\begin{array}{c}\lambda \\
(\operatorname{deg})\end{array}$ & $\begin{array}{c}M_{0} \\
\left(10^{18} \mathrm{~N} \mathrm{~m}\right)\end{array}$ & $M_{\mathrm{w}}$ \\
\hline $\mathrm{a}$ & 930515 & RE & 16.70 & -98.40 & 21 & 314 & 18 & 90 & 1.70 & 6.0 \\
\hline b & 931024 & $\mathrm{RE}$ & 16.76 & -98.72 & 21 & 303 & 15 & 90 & 12.00 & 6.6 \\
\hline $\mathrm{c}$ & 960715 & $\mathrm{RE}$ & 17.50 & -101.12 & 22 & 297 & 21 & 93 & 9.95 & 6.6 \\
\hline d & 990930 & NO & 16.03 & -96.96 & 47 & 299 & 49 & -79 & 140.00 & 7.4 \\
\hline $\mathrm{e}$ & 991229 & NO & 18.00 & -101.63 & 50 & 122 & 74 & -78 & 0.86 & 5.9 \\
\hline f & 940523 & NO & 18.02 & -100.57 & 50 & 273 & 39 & -76 & 3.60 & 6.2 \\
\hline $\mathrm{g}$ & 970522 & NO & 18.37 & -101.82 & 54 & 269 & 63 & -96 & 6.53 & 6.5 \\
\hline $\mathrm{h}$ & 990615 & NO & 18.13 & -97.54 & 61 & 309 & 40 & -83 & 22.00 & 6.9 \\
\hline $\mathrm{i}$ & 980420 & NO & 18.35 & -101.19 & 64 & 290 & 60 & -85 & 1.01 & 5.9 \\
\hline
\end{tabular}

Hypocenter location and focal mechanism for the normal intermediate events were obtained from local data. The other parameters were obtained from the Harvard Centroid Moment Tensor Catalog (Dziewonski et al., 1981). RE, reverse-faulting earthquake; NO, normal-faulting earthquake.

waves, while $m_{\mathrm{b}}(L g)$ is based on maximum amplitude during the entire $L g$ phase. If earthquakes initiate with a small subevent and cascade, progressively, into larger subevents, as appears to be the case, then $m_{\mathrm{b}}$ cannot measure the true size of large earthquakes. As shown by Houston and Kanamori (1986), a magnitude scale based on maximum amplitude during the entire short-period, teleseismic $P$-wave train, their modified magnitude, $\hat{m}_{\mathrm{b}}$, does not saturate. Thus, we believe that the difference in the scaling and the saturation of $m_{\mathrm{b}}$ may not be evidence for a lack of similarity between teleseismic and regional source spectra.

We correct each of the spectra for attenuation, geometrical spreading, and radiation pattern effects. Assuming the source spectra are the same, parts of the spectrum with large differences in the two spectra should point to possible sources of the regional versus teleseismic discrepancy. We take the ratio of the mean corrected spectra for the regional and teleseismic data. We find the largest discrepancies be- 


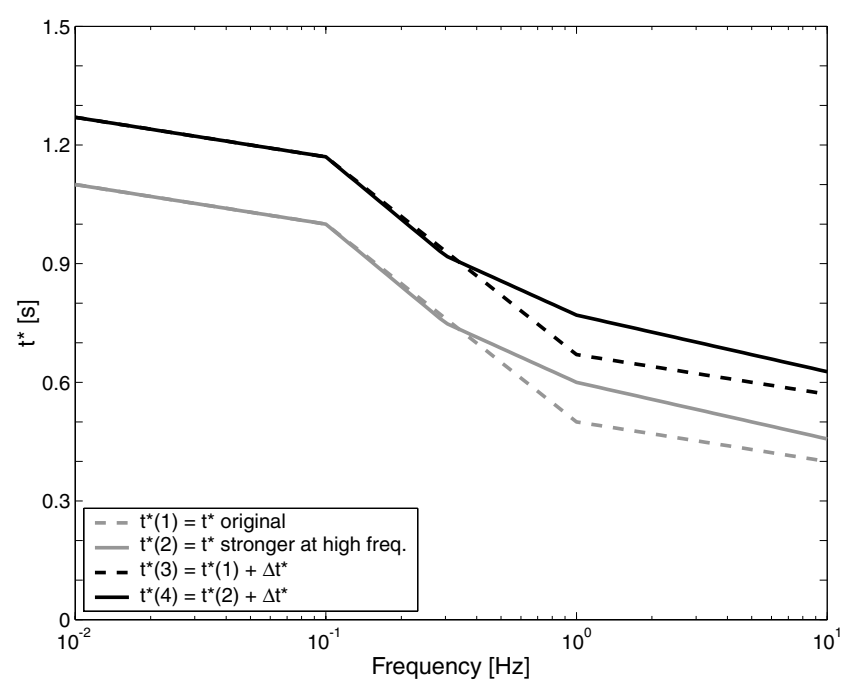

Figure 3. Teleseismic attenuation model. The gray dashed line is the original attenuation model (equation 5) from Choy and Cormier (1986), the gray solid line is the model described by equation (7), the black dashed line is given by equation (5) plus $\Delta t^{*}$ $=0.17$, and the black solid line is the preferred model, expressed by equation (7) plus $\Delta t^{*}=0.17$.

tween the spectra at high frequencies $(f>0.5 \mathrm{~Hz})$; some events, however, show discrepancies at low frequencies as well. There is considerable uncertainty in both spectra used to form the ratio due to site effects, the attenuation correction (at both regional and teleseismic distances), and the geometrical spreading factor so it is not immediately clear which spectrum, if either, is more reliable. We now investigate whether reasonable changes to assumed propagation corrections can explain the observed discrepancies in the spectra and thus the discrepancies in estimates of the radiated energy.

We gauge the improvement by the extent to which the new corrections result in a convergence of the two estimates. While introducing extra degrees of freedom into the problem has the potential to decrease the discrepancy, and hence yield more consistent measurements, we have no guarantee that the result is more accurate. We believe, however, that the revised estimates are more accurate because there is independent evidence that the new corrections are warranted.

\section{Site Correction}

The spectrum comparison leads us to a frequency-dependent difference that can be partially attributed to site effects produced by the material in the shallow crust. Site effects are expected to occur and have a strong influence on seismic amplitudes, but they are not accounted for in many studies of seismic energy. Boatwright et al. (2002) demonstrated how important they can be. We applied site corrections using the combined effect of frequency-dependent site amplification and site attenuation,

$$
A(f)=A_{0}(f) \mathrm{e}^{-\pi \kappa f}
$$

where $A_{0}(f)$ is the amplification factor and $\kappa$ is the attenuation parameter (Anderson and Hough, 1984; Boore, 1996; Boore and Joyner, 1997).

The site amplification should be estimated from the velocity structure of the crust at each station. We did not have that information available, so for the regional data we used only stations located on hard rock, as determined by Quass et al. (1993), and adopted the generic rock type amplification factor of Boore and Joyner (1997). In addition, we used an average attenuation parameter appropriate for the station (Table 1), with $\kappa$ values obtained from previous studies (Castro et al., 1990; Humphrey and Anderson, 1992). If the value of $\kappa$ was unknown, we used an average of $\kappa=0.0306$ sec (Castro et al., 1990; Humphrey and Anderson, 1992). For the teleseismic stations we used a very hard rock amplification factor to correct for the site effect and $\kappa=0.01$ sec (Boore and Joyner, 1997).

\section{Teleseismic Attenuation}

The discrepancies in the spectra and $E_{\mathrm{s}}$ values are much smaller after the site corrections are applied (Figs. 4 and 5); however, the ratio of the spectra still exhibits discrepancies, especially at high frequencies, suggesting that a modification of $t^{*}$ may be necessary as well. We tested a second attenuation model, given by the upper bound of the model from Choy and Cormier (1986), which is stronger at frequencies above $0.3 \mathrm{~Hz}$ :

$$
t^{*}= \begin{cases}0.9-0.1 \log (f) & f<0.1 \mathrm{~Hz} \\ 0.476-0.524 \log (f) & 0.1<f<0.3 \mathrm{~Hz} \\ 0.6+\frac{0.6}{\log (0.3)} \log (f) & 0.3<f<1.0 \mathrm{~Hz} \\ 0.6-\frac{0.1}{\log (5)} \log (f) & 1.0<f \mathrm{~Hz}\end{cases}
$$

(Choy and Cromier, 1986). Boatwright and Choy (1989) observed that attenuation was stronger for subduction-zone earthquakes, such as in Japan, which is consistent with our observed spectral differences at high frequencies; however, the correction given by equation (7) is not large enough to explain the remaining spectral discrepancies, leading us to the third and fourth models, given by equations (5) and (7) plus $\Delta t^{*}=0.17 \mathrm{sec}$ applied at all frequencies (Fig. 3). Boatwright et al. (2002) used $\Delta t^{*}=0.14$ to account for the discrepancy between regional and teleseismic estimates of seismic energy for the 1999 Hector Mine earthquake. The difference between attenuation models was concentrated at frequencies above $0.3 \mathrm{~Hz}$. The fourth model brings the spectral ratio at high frequencies closer to unity (Fig. 4), and the values of $E_{\mathrm{s}}$ estimated from the two datasets are more similar as well (Fig. 5). 


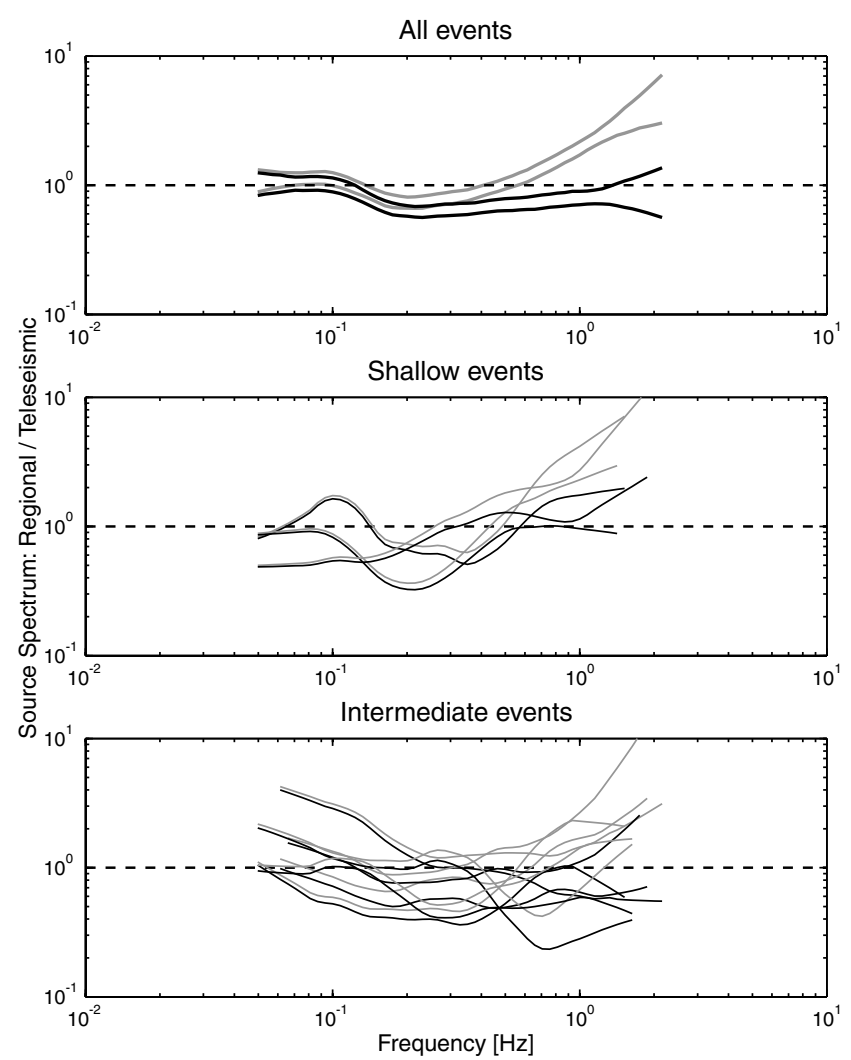

Figure 4. Ratio of regional to teleseismic source spectra. Gray lines: regional and teleseismic source spectra corrected for geometrical spreading, attenuation, and site effect (equations 3 to 6). Black lines: teleseismic $P$-wave spectra corrected for attenuation using $t^{*}$ shown by black solid line in Figure 3 and regional intermediate-depth events corrected for attenuation using equation (8). Thick lines in the top panel represent the $95 \%$ confidence interval for the mean of the ratios. The ratios have been smoothed using a loess function, with a linear interpolation and a 0.5 neighborhood parameter (Cleveland, 1993).

\section{Regional Attenuation}

The frequency-dependent ratio of regional to teleseismic source spectra, after correcting for site effect, is well explained by changes to the $t^{*}$ operator. For the regional estimate we retained the $Q(f)$ given by equation (3) for the shallow events analyzed in this article. These three events are along the coast of Guerrero and recorded at stations also located both along the coast and inland in Guerrero, resulting in similar propagation paths to the events used by Ordaz and Singh (1992) to obtain their estimate of $Q(f)$. The intermediate-depth events, however, are inland and the propagation paths are different from those analyzed by Ordaz and Singh (1992). García Jiménez (2001) obtained a $Q(f)$ model for intraplate events in central Mexico using the six intraplate events analyzed in this study plus several others. He obtained a frequency-dependent model for $Q(f)$ given by

$$
Q(f)=276 f^{0.57},
$$

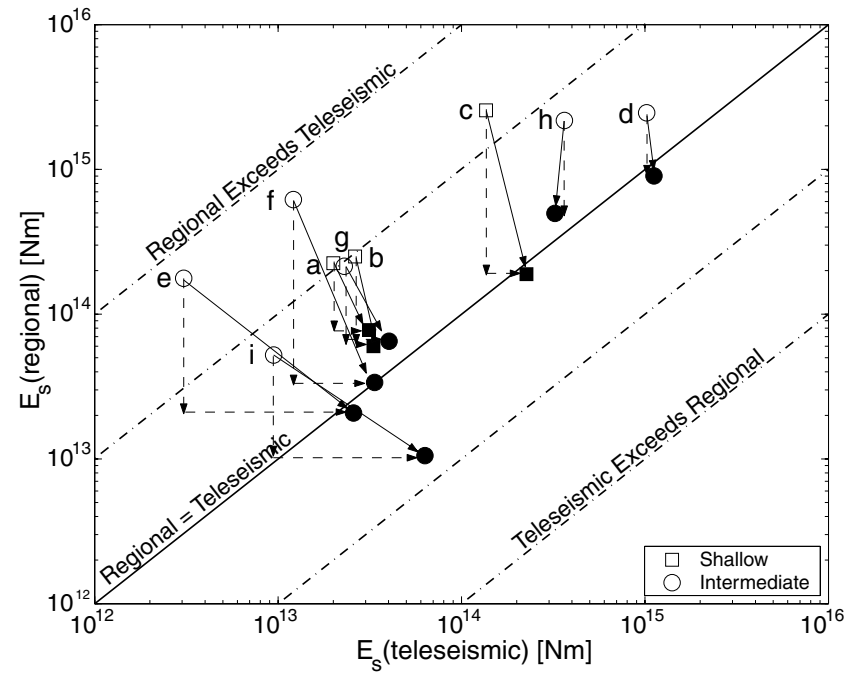

Figure 5. Effect of improved corrections to regional and teleseismic estimates of seismic energy for the earthquakes we studied. Open symbols are the original values, obtained using the corrections given by equations (3) to (5). Vertical dashed arrows represent the effect of the site effect correction for the regional estimates, and the horizontal dashed arrows represent the combination of the site effect correction and the attenuation correction for the teleseismic estimates. Filled symbols are the values after applying all corrections. The letter next to the symbol corresponds to that in Table 2. Black solid arrows represent the total effect after applying the preferred corrections to both regional and teleseismic estimates.

which we used for the intermediate depth events. This attenuation factor is different than that given by equation (3), having a weaker frequency dependence, which translates into a smaller attenuation correction at frequencies below $\sim 1 \mathrm{~Hz}$, but a slightly larger correction at higher frequencies.

\section{Geometrical Spreading}

Boatwright et al. (2002) noted that the mode of wave propagation at regional distances is a strong function of frequency and adopted a frequency-dependent correction to the geometrical spreading factor that uses a fixed crossover distance, $R_{0}$, to account for this. By making that correction and adjusting the teleseismic attenuation to the third model described earlier, they were able to reconcile the discrepancy between regional and teleseismic estimates of the radiated seismic energy for the Hector Mine earthquake.

We have accounted for the frequency discrepancy in the spectra already, by using the frequency-dependence of $Q(f)$ and a frequency-dependent site correction. Analyzing singlestation energy estimates with respect to the distance from the hypocenter to the station, we found that the use of a constant crossover distance, $R_{0}=100 \mathrm{~km}$, and a geometrical spreading correction that is frequency independent produces no systematic variation of the residuals with distance. This suggests that the same crossover distance is adequate for 
both the shallow- and intermediate-depth events in Mexico. The crossover distance of $100 \mathrm{~km}$ was originally estimated empirically by Street et al. (1975) for $L g$ waves from earthquakes in the central United States. Humphey and Anderson (1992) and Castro et al. (1990) explored the effect of the geometrical spreading correction and found that $R_{0}=100$ $\mathrm{km}$ was appropriate for events in Mexico. The estimate of $Q(f)$ for shallow-depth events was done under the assumption of $R_{0}=100 \mathrm{~km}$, such that the two corrections are closely intertwined in previous analyses.

\section{Discussion}

Comparing the source spectra using the corrections detailed earlier for site amplification and attenuation, the discrepancy between the spectra is greatly reduced, especially at high frequencies (Fig. 4). Also, the difference between the regional and teleseismic energy estimate is much smaller (Figs. 5 and 6). The most significant correction is the one due to the site amplification at regional distances (vertical dashed arrows in Fig. 5). By correcting for that we reduced the difference between estimates from a factor of $\sim 11$ to a factor of $\sim 3$ (Fig. 6). Neglecting site effects led to strongly overpredicting the energy based on regional data, while for the teleseismic estimates this effect was much smaller. The choice of a teleseismic attenuation model that attenuates waves more strongly at frequencies above $0.3 \mathrm{~Hz}$ further reduces the difference between estimates to the point where they are very similar (Fig. 6). The selection of this model is supported by independent observations for the subduction zone of Japan (Boatwright and Choy, 1989). The effect of the revised attenuation correction was stronger for the smaller events but not significant for the larger events because of the low corner frequency of the large earthquakes and high corner frequency of the small ones. The combined effect of the site correction and the attenuation correction at teleseismic distances increases the value of $E_{\mathrm{s}}$ estimated from teleseismic data (horizontal dashed arrows in Fig. 5), and the attenuation correction is somewhat larger than the site effect for these data.

There are still some differences between the spectra and discrepancies in the seismic energy estimates, but these are small enough to have a variety of possible causes. In our analysis, the discrepancy was resolved by reducing the regional estimates more than by increasing the teleseismic estimates. In the original dataset, the larger discrepancy and thus the larger correction was for the smaller earthquakes (e.g., event e in Table 2), which is attributable to the strong effect of our corrections at high frequencies, since smaller earthquakes have higher corner frequencies. The largest difference now corresponds to the deepest earthquake (event $\mathrm{i}$ in Table 2), which is also among the smaller events we analyzed; however, now the sense of the discrepancy is reversed, with the teleseismic estimate exceeding the regional estimate by a factor of approximately 6 .

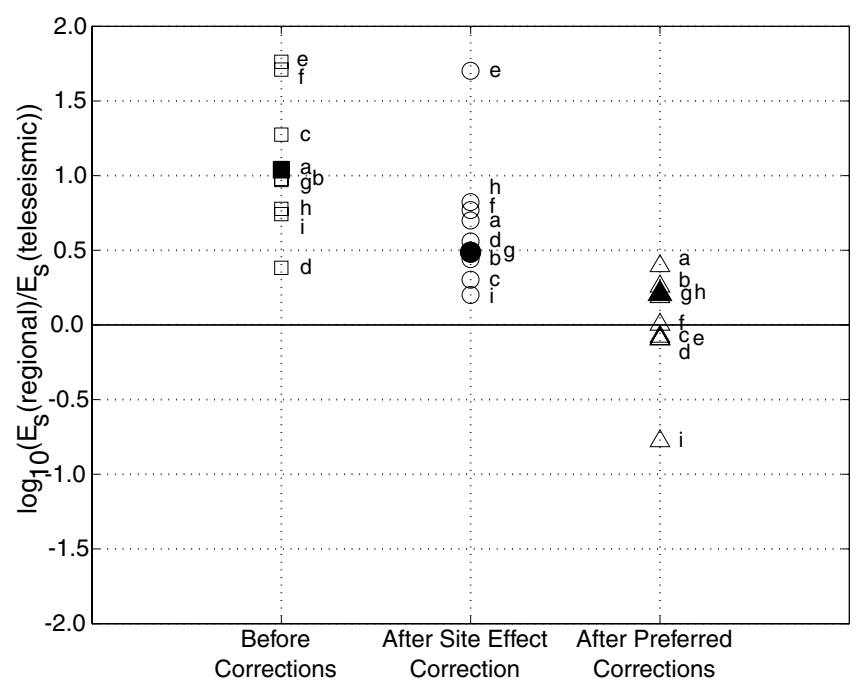

Figure 6. Measure of discrepancy. The discrepancy is measured as the log of the ratio between estimates. The squares are the original estimates, the circles are after applying the site effect correction to both regional and teleseismic data, and the triangles are after applying all preferred corrections. The open symbols are the log ratios of the regional to teleseismic estimate difference for each event. The letter next to the symbol corresponds to that in Table 2. Filled symbols are the median of the ratios. The solid line denotes estimates from regional and teleseismic data that are equal.

\section{Conclusions}

The site amplification effect is an important factor and must be taken into account when estimating the seismic energy, not only for those stations that are located on soft rock or soils or for stations that are known to have strong site effects for other reasons, but even at rock sites. Overestimation of the seismic energy can be significant if the site effect is not accounted for.

The attenuation correction is also important and needs to be calibrated both for teleseismic and regional estimates. Ideally, the attenuation model should come from independent data appropriate to the source-receiver path.

With our corrections we were able to reduce the difference between the regional and teleseismic estimates of the seismic energy from a median factor of $\sim 11$ to a median factor of $\sim 1.6$. Thus, our results suggest that more precise estimates of the seismic energy are now attainable. This can be tested with data from future earthquakes, which will be better recorded both locally and globally. The question of how to be sure we are obtaining more accurate estimates of the seismic energy is more difficult, but the improved data coverage will help there, too.

\section{Acknowledgments}

We thank J. Boatwright for his inspiring discussions and suggestions. We thank two anonymous reviewers and Michael Fehler for their comments 
and suggestions as well. This research was supported by NSF grant EAR 9909479 and NSF grant EAR 0208499. Xyoli Pérez-Campos was partially supported by the Blaustein fellowship; the Robert G. Kirby fellowship; SEP, Mexico; and DGAPA, UNAM. Shri K. Singh was partly supported by DGAPA project IN111601. Teleseismic data were obtained from the Global Seismic Network, and regional data were obtained from the Base Mexicana de Datos de Sismos Fuertes from stations operated by CENAPRED; Instituto de Geofísica, UNAM; and Instituto de Ingeniería, UNAM, Mexico.

\section{References}

Abercrombie, R. E. (1995). Earthquake source scaling relationships from -1 to $5 M_{\mathrm{L}}$ using seismograms recorded at 2.5-km depth, J. Geophys. Res. 100, 24,015-24,036.

Anderson, J. G., and S. E. Hough (1984). A model for the shape of the Fourier amplitude spectrum of acceleration at high frequencies, Bull. Seism. Soc. Am. 74, 1969-1993.

Boatwright, J., and G. L. Choy (1986). Teleseismic estimates of the energy radiated by shallow earthquakes, J. Geophys. Res. 91, 2095-2112.

Boatwright, J., and G. L. Choy (1989). Acceleration spectra for subduction zone earthquakes, J. Geophys. Res. 94, 15,541-15,553.

Boatwright, J., G. L. Choy, and L. C. Seekins (2002). Regional estimates of the radiated seismic energy, Bull. Seism. Soc. Am. 92, 1241-1255.

Boore, D. M. (1996). SMSIM-Fortran programs for simulating ground motions from earthquakes: version 1.0, U.S. Geol. Surv. Open-File Rept. 96-80A, 96-80-B, 69 pp.

Boore, D. M., and W. B. Joyner (1997). Site amplifications for generic rock sites, Bull. Seism. Soc. Am. 87, 327-341.

Castro, R. R., J. G. Anderson, and S. K. Singh (1990). Site response, attenuation, and source spectra of $S$ waves along the Guerrero, Mexico subduction zone, Bull. Seism. Soc. Am. 80, 1481-1503.

Choy, G. L., and J. Boatwright (1995). Global patterns of radiated seismic energy and apparent stress, J. Geophys. Res. 100, 18,205-18,226.

Choy, G. L., and V. F. Cormier (1986). Direct measurement of the mantle attenuation operator from broadband $P$ and $S$ waveforms, J. Geophys. Res. 91, 7326-7342.

Cleveland, W. S. (1993). Visualizing Data, Hobart Press, Summit, N.J., $360 \mathrm{pp}$.

Dreger, D., and A. Kaverina (2000). Seismic remote sensing for the earthquake source process and near-source strong shaking: a case study of the October 16, 1999 Hector Mine earthquake, Geophys. Res. Lett. 27, 1941-1944.

Dziewonski, A. M., T. A. Chou, and J. H. Woodhouse (1981). Determination of earthquake source parameters from waveform data for studies of global and regional seismicity, J. Geophys. Res. 86, 2825-2852.

García Jiménez, D. (2001). Seismic attenuation: application to intraplate earthquakes in Central Mexico, Master's Thesis, Facultad de Ciencias Físicas, Universidad Complutense de Madrid (in Spanish).

Houston, H., and H. Kanamori (1986). Source spectra of great earthquakes: teleseismic constraints on rupture process and strong motion, Bull. Seism. Soc. Am. 76, 19-42.

Humphrey, J. R., Jr., and J. G. Anderson (1992). Shear-wave attenuation and site response in Guerrero, Mexico, Bull. Seism. Soc. Am. 81, $1622-1645$.

Kanamori, H., J. Mori, E. Hauksson, T. H. Heaton, L. K. Hutton, and L. M. Jones (1993). Determination of earthquake energy release and $M_{\mathrm{L}}$ using terrascope, Bull. Seism. Soc. Am. 83, 330-346.

Kikuchi, M., and Y. Fukao (1988). Seismic wave energy inferred from long-period body wave inversion, Bull. Seism. Soc. Am. 78, 17071724.

Mayeda, K., and W. R. Walter (1996). Moment, energy, stress drop, and source spectra of western United States earthquakes from regional coda envelopes, J. Geophys. Res. 101, 11,195-11,208.

Newman, A. V., and E. A. Okal (1998). Teleseismic estimates of radiated seismic energy: the $E / M_{0}$ discriminant for tsunami earthquakes, J. Geophys. Res. 103, 26,885-26,898.

Ordaz, M., and S. K. Singh (1992). Source spectra and spectral attenuation of seismic waves from Mexican earthquakes, and evidence of amplification in the hill zone of Mexico City, Bull. Seism. Soc. Am. 82, 24-43.

Patton, H. J. (2001). Regional magnitude scaling, transportability, and $M_{\mathrm{S}}: m_{\mathrm{b}}$ discrimination at small magnitudes, Pure Appl. Geophys. 158, 1951-2015.

Pérez-Campos, X., and G. C. Beroza (2001). Mechanism dependent scaling of radiated seismic energy, J. Geophys. Res. 106, 11,127-11,136.

Prejean, S. G., and W. L. Ellsworth (2001). Observations of earthquake source parameters and attenuation at $2 \mathrm{~km}$ depth in the Long Valley Caldera, eastern California, Bull. Seism. Soc. Am. 91, 165-177.

Quaas, R., J. A. Otero, S. Medina, J. M. Espinosa, H. Aguilar, and M. González (1993). National database of large earthquake catalogue of accelerograph stations 1960-1992, Sociedad Mexicana de Ingeniería Sísmica, AC (in Spanish).

Shi, J., P. G. Richards, and W. Kim (2000). Determination of seismic energy from $L g$ waves, Bull. Seism. Soc. Am. 90, 483-493.

Singh, S. K., and M. Ordaz (1994). Seismic energy release in Mexican subduction zone earthquakes, Bull. Seism. Soc. Am. 84, 1533-1550.

Street, R. L., R. B. Herrman, and O. W. Nuttli (1975). Special characteristics of the $L_{\mathrm{g}}$ wave generated by central United States earthquakes, Geophys. J. R. Astr. Soc. 41, 51-63.

Venkataraman, A., L. Rivera, and H. Kanamori (2002). Radiated energy from the October 16, 1999 Hector Mine earthquake: regional and teleseismic estimates, Bull. Seism. Soc. Am. 92, 1256-1265.

Department of Geophysics

Stanford University

397 Panama Mall

Stanford, California 94305-2215

(X.P.-C., G.C.B.)

Instituto de Geofísica

UNAM

Ciudad Universitaria

México, D. F. 04510, México

(S.K.S.)

Manuscript received 21 October 2002. 